\title{
Metal-Organic Frameworks Invert Molecular Reactivity: Lewis Acidic Phosphonium Zwitterions Catalyze the Aldol-Tishchenko Reaction
}

\author{
Gerald Bauer, ${ }^{\dagger \odot}$ Daniele Ongari, ${ }^{\ddagger} \odot$ Xiaoying Xu, ${ }^{\dagger}$ Davide Tiana, ${ }^{\ddagger, \delta}$ Berend Smit, ${ }^{\ddagger \oplus}$ \\ and Marco Ranocchiari*, $\dagger$
} \author{
Lausanne (EPFL) Rue de l'Industrie 17, CH-1951 Sion, Switzerland \\ ${ }^{\S}$ School of Chemistry, University College Cork, College Road, Cork, Ireland
}

${ }^{\dagger}$ Laboratory for Catalysis and Sustainable Chemistry, Paul Scherrer Institute, CH-5232 Villigen PSI, Switzerland

${ }^{\ddagger}$ Laboratory of Molecular Simulation (LSMO), Institut des Sciences et Ingénierie Chimiques, Valais Ecole Polytechnique Fédérale de

\section{Supporting Information}

\begin{abstract}
The influence of metal-organic frameworks (MOFs) as additives is herein described for the reaction of $n$-alkyl aldehydes in the presence of methylvinylketone and triphenylphosphine. In the absence of a MOF, the expected Morita-Baylis-Hillman product, a $\beta$-hydroxy enone, is observed. In the presence of MOFs with UMCM-1 and MOF-5 topologies, the reaction is selective to Aldol-Tishchenko products, the 1 and $3 n$ alkylesters of 2-alkyl-1,3-diols, which is unprecedented in organocatalysis. The (3-oxo-2-butenyl)triphenylphosphonium zwitterion, a commonly known nucleophile, is identified as the catalytic active species. This zwitterion favors nucleophilic character in solution, whereas once confined within the framework, it becomes an electrophile yielding Aldol-Tishchenko selectivity. Computational investigations reveal a structural change in the phosphonium moiety induced by the steric confinement of the framework that makes it accessible and an electrophile.
\end{abstract}

$\mathrm{M}$ etal-organic frameworks (MOFs) are becoming increasingly relevant for catalytic applications. ${ }^{1}$ Their structural versatility, tunable pore size and modularity give a nearly infinite number of structures. ${ }^{2}$ MOFs feature active sites as intrinsic parts of the inorganic nodes or organic linkers. Reactive intermediates may also be trapped inside the pores. ${ }^{1 a}$ These features can be thought of providing host-guest properties similar to enzymes giving them potential beyond simple heterogenisation of homogeneous catalysts. Reactivity and selectivity of reactions can be tuned by exploiting the environment around the active site. ${ }^{3}$ For instance, a chiral binaphthyl copper MOF with phosphoric acid functionality can reverse the stereoselectivity in the Friedel-Crafts reaction between indoles and imines. ${ }^{4}$ The cobalt salen-catalyzed intramolecular epoxide ring opening in the presence of a MOF results in the formation of the 6-membered ring, whereas the homogeneous analogue yielded the 5-membered ring product. $^{5}$ Molecular confinement within a phosphine MOF with IRMOF-9 topology has also proven to sterically induce intermediate selectivity to determine which reactions occur. ${ }^{6}$ One can also tune the environment around active sites to affect regioisomer reactivity as demonstrated by amino MixMOFs with IRMOF-9 topology that catalyze the Knøvenagel condensation of nitrobenzaldehydes. The common underlying feature is the anchoring of reaction intermediates to the framework which consequently alters the reaction pathway. We show that we can use the MOF's porous environment to completely alter the reactivity of a catalytic intermediate from nucleophile to electrophile, yielding an as yet unprecedented catalytic pathway.

Hereby, phosphines play a central role in catalytic processes to achieve high reactivity and selectivity. Although their main application lies in the field of transition metal catalyzed reactions, ${ }^{8}$ e.g., the hydroformylation of olefins ${ }^{9}$ and the asymmetric synthesis of fine chemicals and bioactive compounds, ${ }^{10}$ phosphorus compounds gain increasing interest in organocatalytic reactions. ${ }^{11}$ Phosphines as organocatalysts facilitate the reaction with unsaturated carbon atoms to form phosphonium zwitterions. ${ }^{11 \mathrm{~d}}$ Such species are reactive toward nucleophilic attack and catalyze a variety of $\mathrm{C}-\mathrm{C}$ bond forming reactions like the Michael addition and the Morita-BaylisHillman $(\mathrm{MBH})$ reaction. ${ }^{11 \mathrm{a}, \mathrm{d}}$ The phosphonium ion activates the adjacent carbon atoms. Free phosphonium cations are also active Lewis acid catalysts. ${ }^{12}$ The low lying $\sigma^{*}$ orbitals of the P$\mathrm{C}$ bonds make the phosphorus electrophilic. ${ }^{13}$ Even though phosphonium cations have shown to catalyze different coupling reactions, ${ }^{14}$ they are rarely, if ever, the reactive moiety when placed in a zwitterion. Hence, electrophilic reactions, like the Aldol-Tishchenko (AT) reaction, ${ }^{15}$ are usually not accessible via phosphonium zwitterions.

In this contribution, we describe a triphenylphosphonium zwitterionic species that features electrophilicity only when MOFs are present. These findings show that MOFs can completely alter the reactivity of an organocatalyst from a nucleophile in solution to an electrophile in the framework, enabling the AT reaction: an as yet unprecedented reaction in organocatalysis. The role of the framework was subsequently studied by experimental and computational methods. This work shows the capability of MOFs to completely switch the reactivity of the phosphonium zwitterions, thus enabling otherwise inaccessible reaction pathways.

Received: October 13, 2017

Published: December 2, 2017 
Phosphines are commonly used as organocatalysts in the $\mathrm{MBH}$ reaction: electron deficient olefins, such as methyl vinyl ketone (MVK), react in the presence of the nucleophilic $\mathrm{PPh}_{3}$ and aldehydes to form $\beta$-hydroxy enones. ${ }^{16}$ The influence of amino containing MixMOF systems with MOF-5 topology as cocatalysts ${ }^{17}$ in the $\mathrm{PPh}_{3}$-catalyzed $\mathrm{MBH}$ reaction was investigated at first. Experiments in solution of $n$-pentanal and MVK with catalytic amounts of $\mathrm{PPh}_{3}$ showed $15 \%$ conversion of the starting aldehyde with a selectivity of $>99 \%$ toward the corresponding $\mathrm{MBH}$ product, the 4-hydroxy-3-methylene-2octanone (3-C $\mathbf{C}_{4}$ ) (Table 1, Entry 1$)$. When the same reaction was performed with $n$-butanal as substrate in the presence of MixMOF-5- $\mathrm{NH}_{2}\left(13 \mathrm{~mol} \% \mathrm{NH}_{2}\right.$; Figure 1a) three products

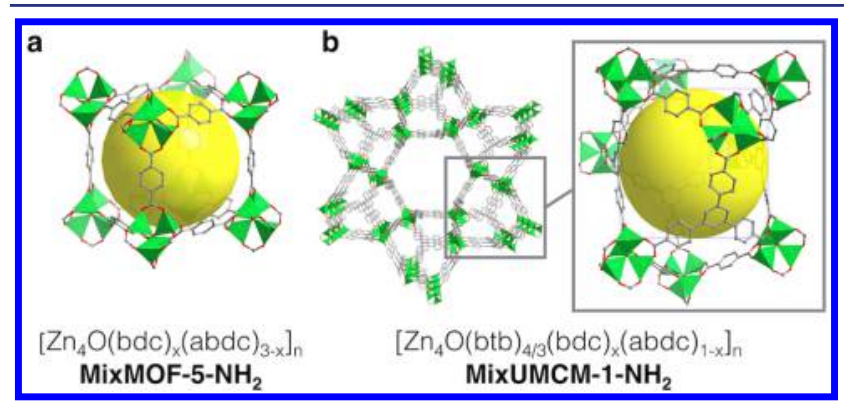

Figure 1. Structures and molecular formulas of the MOFs used in this work: (a) MixMOF-5-NH $\mathrm{NH}_{2}$ and (b) MixUMCM-1-NH 2 . bdc $=1,4-$ benzenedicarboxylate; $\mathrm{abdc}=2$-amino-1,4-benzenedicarboxylate, $\mathrm{btb}=$ $4,4^{\prime}, 4^{\prime \prime}$,-benzene-1,3,5-triyl-trisbenzoic acid (hydrogen and nitrogen atoms were omitted for clarity).

were observed. ${ }^{18}$ In addition to the expected $\mathrm{MBH}$ product, the AT products, the 1- and 3- butanoic acid esters of 2-ethyl-1,3hexandiol $\left(\mathbf{1}-\mathbf{C}_{\mathbf{4}}\right.$ and $\left.\mathbf{2}-\mathbf{C}_{\mathbf{4}}\right){ }^{15}$ were observed as major products with $76 \%$ selectivity (Table 1 , Entry 2 ). The formation of $\mathbf{1}-\mathbf{C}_{4}$ and $\mathbf{2}-\mathrm{C}_{4}$ was confirmed by independent synthesis and analysis of the AT products. ${ }^{19}$

The addition of the amino containing MIL-101(Al $)^{20}$ and DMOF-1- $\mathrm{NH}_{2},{ }^{21}$ yielded only the $\mathrm{MBH}$ product $3-\mathrm{C}_{4} \cdot{ }^{19}$ When MixUMCM-1- $\mathrm{NH}_{2}\left(28 \mathrm{~mol} \% \mathrm{NH}_{2} \text {; Figure } 1 \mathrm{~b}\right)^{21,22}$ was used as additive, the conversion increased to $70 \%$ and the AT selectivity to $82 \%$ (Table 1, Entry 3). The role of the amino substituent was further investigated. MixUMCM-1- $\mathrm{NH}_{2}$ with 28 to $100 \mathrm{~mol}$ $\% \mathrm{NH}_{2}$ were employed (Table 1, Entries 3-5). Increasing the amino content in the MOF to $52 \mathrm{~mol} \% \mathrm{NH}_{2}$ (Table 1, Entry 4) enhanced the AT selectivity to $84 \%$ with an $87 \%$ conversion. The fully functionalized UMCM-1- $\mathrm{NH}_{2}$ (Table 1, Entry 5) significantly reduced conversion to $14 \%$ with an AT selectivity of $63 \%$. Reaction with nonfunctionalized UMCM-1 showed a conversion of $84 \%$ with a respective AT selectivity of $75 \%$ (Table 1, Entry 6). These results indicate that the amino residue influence AT reactivity and selectivity. The UMCM-1 with around $50 \mathrm{~mol} \% \mathrm{NH}_{2}$, equivalent of one functional group per pore, is optimal for conversion and selectivity.

The substrate scope was then extended using a series of different $n$-aliphatic aldehydes with increasing chain lengths. The use of $n$-pentanal and $n$-hexanal reduced the overall conversion to $58 \%$ and $56 \%$, respectively, with an AT selectivity of $84 \%$ in both cases (Table 1, Entries 7 and 8 ). $n$-Heptanal yielded a conversion of $34 \%$ with a corresponding AT selectivity of $62 \%$ (Table 1, Entry 9). Increasing the chain length of the aldehyde limits the conversion, giving further evidence that AT catalysis takes place inside the framework. Blank reactions using dimethyl aminoterephthalate-as a substitute for the amino
Table 1. Reactivity and Selectivity of Various $n$-Aliphatic Aldehydes in the Presence of $\mathrm{PPh}_{3}$ and MVK Using Different MixMOF- $\mathrm{NH}_{2}$ Systems as Cocatalysts

\begin{tabular}{|c|c|c|c|c|c|}
\hline \multirow[b]{3}{*}{ Entry } & \multirow[b]{3}{*}{ MOF } & \multirow[b]{3}{*}{ Aldehyde } & \multirow[b]{3}{*}{$\begin{array}{l}\text { Conv. } \\
{[\%]^{a}}\end{array}$} & \multicolumn{2}{|c|}{$\begin{array}{l}\text { Selectivity } \\
{[\%]^{b}}\end{array}$} \\
\hline & & & & $1-C_{n}$ & \\
\hline & & & & $2-C_{n}$ & $3-\mathrm{C}_{n}$ \\
\hline 1 & - & $\begin{array}{c}n \text {-pentanal } \\
\left(\mathrm{R}=\mathrm{C}_{3} \mathrm{H}_{7}\right)\end{array}$ & 15 & 0 & $>99$ \\
\hline 2 & $\begin{array}{l}\text { MixMOF-5-NH } \\
\quad\left(13 \mathrm{~mol} \% \mathrm{NH}_{2}\right)\end{array}$ & $\begin{array}{l}n \text {-butanal } \\
\quad\left(\mathrm{R}=\mathrm{C}_{2} \mathrm{H}_{5}\right)\end{array}$ & 47 & 76 & 14 \\
\hline 3 & $\begin{array}{r}\operatorname{MixUMCM}-1-\mathrm{NH}_{2} \\
\left(28 \mathrm{~mol} \% \mathrm{NH}_{2}\right)\end{array}$ & $\begin{array}{l}\text { n-butanal } \\
\left(\mathrm{R}=\mathrm{C}_{2} \mathrm{H}_{5}\right)\end{array}$ & 70 & 82 & 14 \\
\hline 4 & 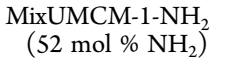 & $\begin{array}{l}n \text {-butanal } \\
\quad\left(\mathrm{R}=\mathrm{C}_{2} \mathrm{H}_{5}\right)\end{array}$ & 87 & 84 & 13 \\
\hline 5 & $\begin{array}{l}\text { UMCM-1-NH } \\
\quad\left(100 \mathrm{~mol} \mathrm{\%} \mathrm{NH}_{2}\right)\end{array}$ & $\begin{array}{l}n \text {-butanal } \\
\quad\left(\mathrm{R}=\mathrm{C}_{2} \mathrm{H}_{5}\right)\end{array}$ & 14 & 63 & 30 \\
\hline 6 & UMCM-1 & $\begin{array}{l}n \text {-butanal } \\
\quad\left(\mathrm{R}=\mathrm{C}_{2} \mathrm{H}_{5}\right)\end{array}$ & 84 & 75 & 21 \\
\hline 7 & $\begin{array}{l}\text { MixUMCM-1-NH } \\
\left(28 \mathrm{~mol} \% \mathrm{NH}_{2}\right)\end{array}$ & $\begin{array}{l}n \text {-pentanal } \\
\quad\left(\mathrm{R}=\mathrm{C}_{3} \mathrm{H}_{7}\right)\end{array}$ & 58 & 84 & 13 \\
\hline 8 & $\begin{array}{r}\operatorname{MixUMCM}-1-\mathrm{NH}_{2} \\
\left(28 \mathrm{~mol} \% \mathrm{NH}_{2}\right)\end{array}$ & $\begin{array}{l}n \text {-hexanal } \\
\quad\left(\mathrm{R}=\mathrm{C}_{4} \mathrm{H}_{9}\right)\end{array}$ & 56 & 84 & 14 \\
\hline 9 & $\begin{array}{l}\text { MixUMCM-1-NH } \\
\left(28 \mathrm{~mol} \% \mathrm{NH}_{2}\right)\end{array}$ & $\begin{array}{l}n \text {-heptanal } \\
\left(\mathrm{R}=\mathrm{C}_{5} \mathrm{H}_{11}\right)\end{array}$ & 34 & 62 & 38 \\
\hline
\end{tabular}

${ }^{a}$ Conversions were determined via GC or UPLC: the starting material was calibrated prior to the analyses. ${ }^{b}$ The amount of product were determined via GC: the values are based on the C-ratios of the respective products. Additional unidentified products were observed. ${ }^{19}$

containing $\mathrm{MOF}-$ and $\mathrm{Zn}^{2+}$ precursors were also performed (Table S8). ${ }^{19}$ All reactions yielded only the $\mathrm{MBH}$ product underlining the pivotal role of the MOF in forming the AT product. The formation of an imine between the dimethyl aminoterephthalate and the aldehyde was not observed. In addition, the amino-free UMCM-1 (Table 1, Entry 6) also showed to induce the selectivity change toward AT reaction, which excludes the formation and the involvement of imines as catalytically relevant entities (Table S8). When MVK and/or $\mathrm{PPh}_{3}$ were omitted from the reaction, neither reaction occurred. ${ }^{19}$ Previous studies showed that $\mathrm{PPh}_{3}$ reacts with MVK to form the zwitterionic species 4 (Figure 2). ${ }^{16,19,23}$ The presence of $\mathbf{4}$ was independently detected by UPLC/MS in the

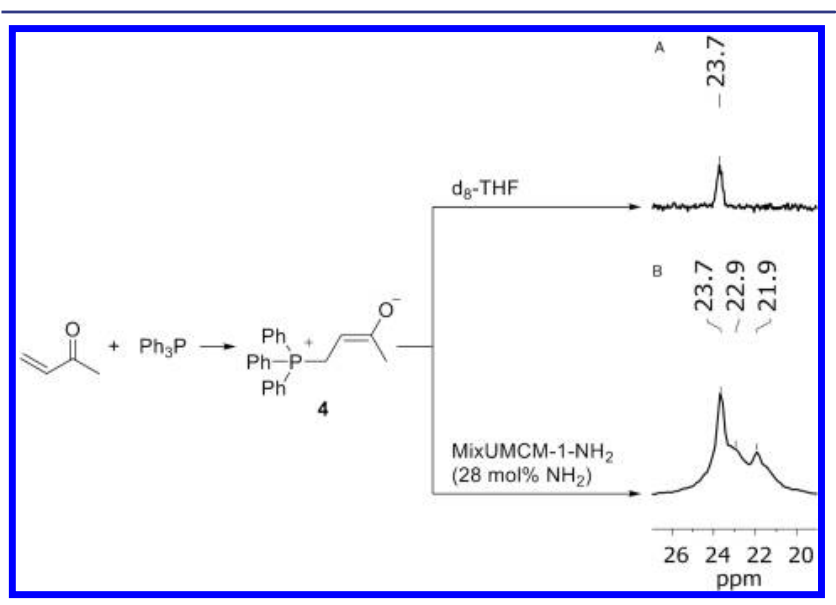

Figure 2. Formation of (3-oxo-2-butenyl) triphenylphosphonium (4) as catalytic active species: (A) MVK $(0.25 \mathrm{mmol})+\mathrm{PPh}_{3}(0.16 \mathrm{mmol})$ in $d_{8}$-THF $(0.5 \mathrm{~mL})$; (B) formation and interaction 4 with MixUMCM-1- $\mathrm{NH}_{2}\left(28 \mathrm{~mol} \% \mathrm{NH}_{2}\right)$. 
crude reaction mixture. ${ }^{19}$ Molecule 4 is an active intermediate in the $\mathrm{MBH}$ reaction and normally acts as a nucleophile. However, in the presence of amino MOFs with MOF-5 and UMCM-1 topologies, this zwitterion becomes an electrophile as required in the AT reaction. ${ }^{15}$

To further prove that (a) the catalytic intermediate is trapped within the MOF and that (b) leads to AT reactivity, MixUMCM-1- $\mathrm{NH}_{2}$ (28 mol \% $\left.\mathrm{NH}_{2}\right)$ was pretreated with $\mathrm{PPh}_{3}$ and MVK in tetrahydrofuran (THF) overnight. It was then intensively washed to remove the excess $\mathrm{MVK}$ and $\mathrm{PPh}_{3}$. A solution with $n$-butanal in THF was introduced thereto. Under these conditions exclusively, the AT product was formed (Table S8). ${ }^{19}$ The absence of the $\mathrm{MBH}$ product excludes the leaching of the catalytic intermediate from the framework. Furthermore, it shows the central role of the MOF in the selectivity change. The interaction between active species and the MOF was then investigated. A stoichiometric mixture of $\mathrm{PPh}_{3}$ and $\mathrm{MVK}$ in $d_{8^{-}}$ THF was measured by ${ }^{31} \mathrm{P}$ NMR spectroscopy showing the formation of a new species at $23.7 \mathrm{ppm}$, which corresponds to the zwitterionic phosphonium species, (3-oxo-2-butenyl)triphenylphosphonium (Figure 2, spectrum A). ${ }^{19,23 \mathrm{~b}}$ When dimethyl aminoterephthalate was added to the solution, the signal shifted downfield to $24.2 \mathrm{ppm} .{ }^{19}$ This is indicative of an interaction between the zwitterion 4 and the amino moiety. Subsequently, the presence of 4 in the MOF structure was confirmed by pretreating MixUMCM-1- $\mathrm{NH}_{2}\left(28 \mathrm{~mol} \% \mathrm{NH}_{2}\right)$ with $\mathrm{PPh}_{3}$ and $\mathrm{MVK}$ in THF after removal of the excess $\mathrm{PPh}_{3}$ and MVK. Solid state ${ }^{31} \mathrm{P}$ NMR spectroscopy (Figure 2, Spectrum B $)^{19}$ shows the formation of three species at 21.9, 22.9 , and $23.7 \mathrm{ppm}$ with chemical shifts comparable to solution spectra of the zwitterion 4 demonstrating that the zwitterion is trapped relatively strong within the MOF pores. ${ }^{1} \mathrm{H}$ NMR spectroscopy after digestion of 4 within MixUMCM-1- $\mathrm{NH}_{2}(42$ mol \% $\mathrm{NH}_{2}$ ) revealed a formula $\left[\mathrm{Zn}_{4} \mathrm{O}\right.$ $\left.(\mathrm{btb})_{4 / 3}(\mathrm{bdc})_{0.58}(\mathrm{abdc})_{0.42}(4)_{0.27}\right]_{n}$ with 0.64 ratio between 4 and amino groups (Figures S9-S11). ${ }^{19}$ The structure of the MOF is maintained upon reaction with intermediate 4, and a surface area decrease of $50 \%$ is observed (Figures S3 and S4). ${ }^{19}$

To understand the role of the framework in the activation of the AT reaction pathway, we compared the catalytically active phosphonium zwitterion 4 in solution as well as in the UMCM1 environment using a mix of density functional theory (DFT) and force field calculations. Intermediate $\mathbf{4}$ can either bind to defect sites in the crystal lattice, enabling a direct coordination to $\mathrm{Zn}^{2+}$ ions, or via hydrogen bonding to the amine group dispersed within the framework. The coordination of the $\mathrm{Zn}$ sites cannot be excluded a priori but it was shown exprimentally that the amine group plays a central role in the anchoring of 4 . Further evidence of the stabilizing role of hydrogen bonds in phosphonium zwitterions is also evidenced in the enantioselective phosphine organocatalysis literature. ${ }^{16}$ Hence, we focused on $\mathrm{H}$-bond stabilization and studied stability of $\mathbf{4}$ in the presence of MixUMCM-1- $\mathrm{NH}_{2}\left(50 \mathrm{~mol} \% \mathrm{NH}_{2}\right.$; system A) and in solution with dimethyl aminoterephthalate (system B; Figure 3). The optimized geometry of systems A and $\mathbf{B}$ was computed using DFT. Inside the MOF, the zwitterion can adopt two different configurations: (A1) pointing toward the pore or (A2) pointing toward the channel (Figure 3). Starting from these configurations, classical molecular dynamics (MD) was used to verify the strength of the $\mathrm{H}$-bond and the possibility of a transition between the states A1 and A2. All the simulations consider liquid $n$-butanal as explicit solvent. In both MixUMCM-1- $\mathrm{NH}_{2}$ systems (A1, A2) and the unhindered

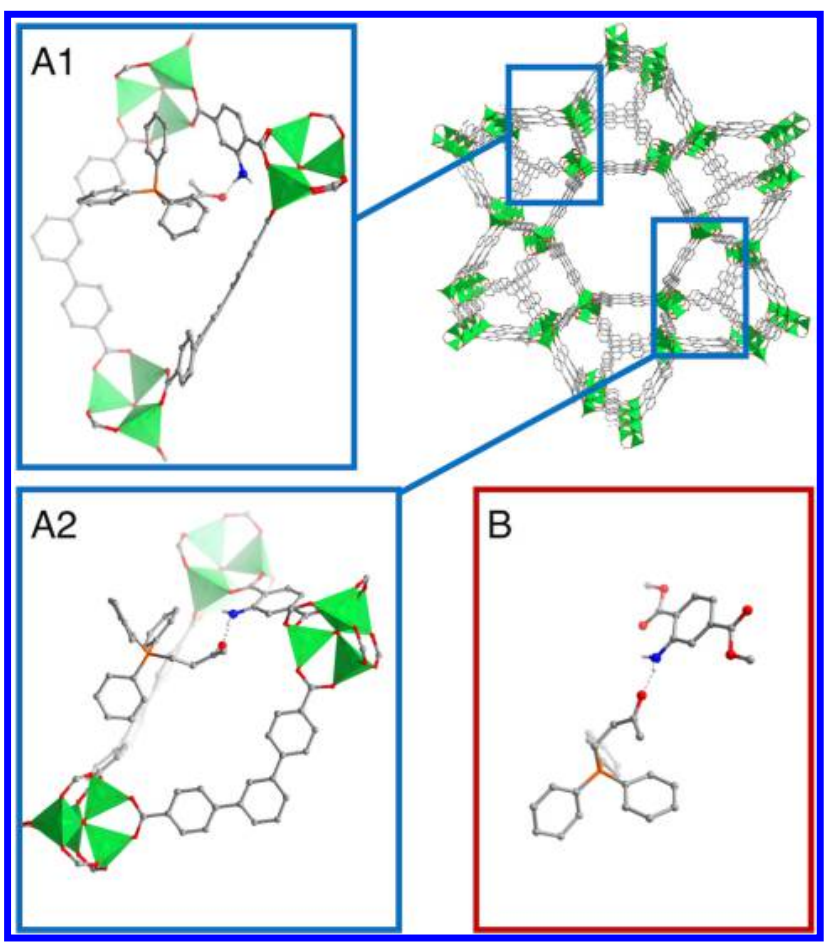

Figure 3. Two different configurations in which the zwitterion (4) can be found inside MixUMCM- $\mathrm{NH}_{2}$, anchored by an $\mathrm{H}$ bond to the amino group: $\mathbf{4}$ is trapped inside the pore (A1); $\mathbf{4}$ points toward the channel (A2). The dimethyl aminoterephthalate system (B, "solution"). H atoms were omitted for clarity reasons.

system (B) the $\mathrm{H}$ bond was found to be stable, i.e., the zwitterion stayed bound to the amine group for the entire simulation (50 ns). A transition between the pore and the channel conformation was not observed, suggesting that a possible transformation from A1 to $\mathbf{A} 2$ only goes via the cleavage of the hydrogen bond.

To derive different reaction pathways, the $\mathrm{C} \cdots \mathrm{C}$ and the $\mathrm{O} \cdots \mathrm{P}$ (Figure S12) ${ }^{19}$ distances were investigated in systems A1, A2 and $\mathbf{B}$. These distances represent the first step of $\mathrm{MBH}$ and AT reaction pathway, respectively. ${ }^{24}$ In this analysis, we consider that the transition state of the reactions is reached when the $d_{\mathrm{Cc}-\mathrm{C} \beta}$ and $d_{\mathrm{O}-\mathrm{P}}$ distances are smaller than the respective C...C and $\mathrm{O} \cdots \mathrm{P}$ van der Waals distances, i.e., 3.47 and $3.36 \AA$. The probability of the transition state can therefore be compared between the different systems. The probability of the C...C distance between the zwitterion and the carbonyl to be shorter than the respective van der Waals distance is in a similar range for the system A2 and B (Table S9). Hence, the steric confinement of the MOF does not play a major role in the suppression of the $\mathrm{MBH}$ pathway. On the other hand, the $d_{\mathrm{O}-\mathrm{P}}$ distance shows a remarkable enhancement inside the MOF: in system A2, the probability related to the formation of the AT precursor is 26 times higher than in system $\mathbf{B}$. This difference in the binding of the $\mathrm{O} \cdots \mathrm{P}$ arises from the interaction between the phenyl groups of the phosphonium and the steric confinement of the MOF. The three phenyl groups cause a significant steric hindrance, which results in the shielding the phosphorus from the $n$-butanal. However, the MOF limits the freedom of movement of 4 , distorting the tetrahedral configuration of the phosphonium moiety. This distortion enables the oxygen attack by the $n$-butanal due to the attractive electrostatic interaction between the oppositely charged $\mathrm{O}(-0.278)$ and $\mathrm{P}(0.523)$ 
atoms. On the other side, the configuration with the zwitterion shielded inside the pores of the MOF (A1) is shown not to be reactive, giving similar results to the $\mathbf{B}$ system (Table S9). MD simulations confirm the active role of the MOF in alternating the zwitterion's reactivity in $\mathbf{A} \mathbf{2}$ as result of the steric interaction arising between the ligands of the frameworks and the phenyl rings.

We have shown that MOFs can effectively bind reaction intermediates and influence the reactivity of catalytic systems. In our case, the Morita-Baylis-Hillman (MBH) reaction of $n$ aliphatic aldehydes with methyl vinyl ketone and $\mathrm{PPh}_{3}$ can be switched to exclusively yield the Aldol-Tishchenko (AT) reaction in the presence of amino containing MixMOFs. This change in reactivity was shown on a series of different $n$-aliphatic aldehydes in various framework systems. The (3-oxo-2butenyl)triphenylphosphonium zwitterion (4), a commonly known nucleophile, was identified as catalytic active species. MixUMCM-1- $\mathrm{NH}_{2}$ confines the zwitterionic organocatalyst and influences the geometry around the tetrahedral phosphonium moiety. Simulations suggested the MOF to affect the fine structure around the phosphonium through new steric interactions between the host (MOF) and the guest (zwitterion), which opens the phosphonium moiety to nucleophilic attack. This work shows a novel way of doing catalysis where MOFs can be used as additive to trap reaction intermediates yielding unprecedented reactivity inaccessible under standard reaction conditions.

\section{ASSOCIATED CONTENT}

\section{S Supporting Information}

The Supporting Information is available free of charge on the ACS Publications website at DOI: 10.1021/jacs.7b10928.

Experimental details (PDF)

\section{AUTHOR INFORMATION}

\section{Corresponding Author}

*marco.ranocchiari@psi.ch

\section{ORCID}

Gerald Bauer: 0000-0003-1412-3901

Daniele Ongari: 0000-0001-6197-2901

Davide Tiana: 0000-0002-3627-1561

Berend Smit: 0000-0003-4653-8562

Marco Ranocchiari: 0000-0002-4460-8742

\section{Notes}

The authors declare no competing financial interest.

\section{ACKNOWLEDGMENTS}

This work was supported by a grant from the Swiss National Supercomputing Centre (CSCS) under Project no. s611. The research of D.O. was supported by the European Research Council (ERC) under the European Union's Horizon 2020 research and innovation programme (grant agreement No. 666983, MaGic). D.T. and G.B. acknowledge the National Centre of Competence in Research (NCCR) "Materials' Revolution: Computational Design and Discovery of Novel Materials (MARVEL)" of the Swiss National Science Foundation (SNSF) which funded their work at EPFL and PSI. We thank Prof. van Bokhoven and Dr. Thomas Wiegand for multiple discussions.

\section{REFERENCES}

(1) (a) Ranocchiari, M.; van Bokhoven, J. A. Phys. Chem. Chem. Phys. 2011, 13, 6388-6396. (b) Gascon, J.; Corma, A.; Kapteijn, F.; Llabrés i Xamena, F. X. ACS Catal. 2014, 4, 361-378.

(2) (a) Yaghi, O. M.; O'Keeffe, M.; Ockwig, N. W.; Chae, H. K.; Eddaoudi, M.; Kim, J. Nature 2003, 423, 705. (b) Gangu, K. K.; Maddila, S.; Mukkamala, S. B.; Jonnalagadda, S. B. Inorg. Chim. Acta 2016, 446, 61-74. (c) Wang, C.; Liu, D.; Lin, W. I.Am. Chem. Soc. 2013, 135, 13222-13234.

(3) (a) Morris, R. E.; Bu, X. Nat. Chem. 2010, 2, 353-361. (b) Nath, I.; Chakraborty, J.; Verpoort, F. Chem. Soc. Rev. 2016, 45, 4127-4170.

(4) Zheng, M.; Liu, Y.; Wang, C.; Liu, S. B.; Lin, W. B. Chem. Sci. 2012, 3, 2623-2627.

(5) Zhang, T.; Song, F.; Lin, W. Chem. Commun. 2012, 48, 8766.

(6) Xu, X.; Rummelt, S. M.; Morel, F. L.; Ranocchiari, M.; van Bokhoven, J. A. Chem. - Eur. I. 2014, 20, 15467-15472.

(7) Xu, X.; van Bokhoven, J. A.; Ranocchiari, M. Chem CatChem 2014, 6, 1887-1891.

(8) (a) de Meijere, A.; Diederich, F. Metal-Catalyzed Cross-Coupling Reactions, Second Completely Revised and Enlarged ed.; Vol. 2; WileyVCH Verlag GmbH \& Co. KGaA: Weinheim, Germany, 2004. (b) Phosphorus(III) Ligands in Homogeneous Catalysis: Design and Synthesis; Kamer, P. C. J., van Leeuwen, P. W. N. M., Eds.; John Wiley \& Sons Ltd.: Chichester, U. K., 2012.

(9) (a) Tudor, R.; Ashley, M. Platinum Met. Rev. 2007, 51, 116-126. (b) Tudor, R.; Ashley, M. Platinum Met. Rev. 2007, 51, 164-171.

(10) Beller, M.; Blaser, H.-U. Organometallics as Catalvsts in the Fine Chemical Industrvi Springer-Verlag: Berlin Heidelberg, 2012.

(11) (a) Fan, Y. C.; Kwon, O. Chem. Commun. 2013, 49, 1158811619. (b) Xiao, Y.; Sun, Z.; Guo, H.; Kwon, O. Beilstein J. Org. Chem. 2014, 10, 2089-2121. (c) Fraile, A.; Parra, A.; Tortosa, M.; Alemán, I. Tetrahedron 2014, 70, 9145-9173. (d) Wang, T.; Han, X.; Zhong, F.; Yao, W.; Lu, Y. Acc. Chem. Res. 2016, 49, 1369-1378.

(12) Bayne, J. M.; Stephan, D. W. Chem. Soc. Rev. 2016, 45, 765-774.

(13) (a) LaFortune, J. H. W.; Johnstone, T. C.; Perez, M.; Winkelhaus, D.; Podgorny, V.; Stephan, D. W. Dalton Trans. 2016, 45, 18156-18162. (b) Sereda, O.; Tabassum, S.; Wilhelm, R. Top. Curr. Chem. 2009, 291, 349-393.

(14) (a) Teruaki, M.; Kouichi, K.; Shigekazu, M. Chem. Lett. 1989, 18, 1397-1400. (b) Teruaki, M.; Shigekazu, M.; Kouichi, K. Chem. Lett. 1989, 18, 993-996. (c) Samzadeh-Kermani, A. Sunlett 2016, 27, 22132216. (d) Werner, T. Adv. Sunth. Catal. 2009, 351, 1469-1481. (e) Garcia-Garcia, P. In Lewis Acid Organocatalysts Other than Ketone and Iminium Salt Catalysts; Georg Thieme Verlag: Stuttgart, 2012; pp $831-869$.

(15) Koskinen, A. M. P.; Kataja, A. O. The Tishchenko Reaction in Org. React.; John Wiley \& Sons, Inc.: New York, 2015, 86, 105-409.

(16) Menozzi, C.; Dalko, P. I. Morita-Baylis-Hillman Reactions. In Enantioselective Organocatalysis: Reactions and Experimental Procedures; Dalko, P. I., Ed.; Wiley-VCH Verlag GmbH \& Co. KGaA: Weinheim, Germany, 2007; pp 151-187.

(17) (a) Luan, Y.; Zheng, N. N.; Qi, Y.; Tang, J.; Wang, G. Catal. Sci. Technol. 2014, 4, 925-929. (b) Miao, Z. C.; Qi, C.; Wensley, A. M.; Luan, Y. RSC Adv. 2016, 6, 67226-67231.

(18) $\mathrm{Mol} \% \mathrm{NH}_{2}$ refers to $\%$ aminoterephthalate to total terephthalate content.

(19) See the Supporting Information.

(20) Serra-Crespo, P.; Ramos-Fernandez, E. V.; Gascon, J.; Kapteijn, F. Chem. Mater. 2011, 23, 2565-2572.

(21) Wang, Z.; Tanabe, K. K.; Cohen, S. M. Inorg. Chem. 2009, 48, 296-306.

(22) Koh, K.; Wong-Foy, A. G.; Matzger, A. I. Angew. Chem.. Int. Ed. 2008, 47, 677-680.

(23) (a) Shi, M.; Chen, L.-H.; Li, C.-Q. I. Am. Chem. Soc. 2005, 127, 3790-3800. (b) Lindner, C.; Liu, Y.; Karaghiosoff, K.; Maryasin, B.; Zipse, H. Chem. - Eur. I. 2013, 19, 6429-6434.

(24) Mahrwald, R. The Aldol-Tishchenko Reaction. In Modern Aldol Reactions; Mahrwald, R., Ed.; Wiley-VCH Verlag GmbH: Weinheim, Germany, 2008; pp 327-344. 